\title{
Effects of 16,16-Dimethyl Prostaglandin E2 on Surface Epithelial Cell Damage in the Rat Stomach Induced by Vagal Nerve Stimulation
}

\author{
Tomochika OHNO, Hiroshi URAMOTO, Takafumi ISHIHARA \\ and Susumu OKABE* \\ Laboratory of Experimental Pharmacology. Suntory Institute for Biomedical Research. \\ 1-1-1 Wakayamadai, Shimamoto-cho. Mishima-gun, Osaka 618, Japan \\ *Department of Applied Pharmacology, Kyoto Pharmaceutical University. \\ Misasagi, Yamashina, Kyoto 607, Japan \\ Accepted January 9, 1987
}

\begin{abstract}
The effect of 16,16-dimethyl prostaglandin $E_{2}$ (dmPGE $E_{2}$ ) on gastric surface epithelial cell (SEC) damage induced by vagal nerve stimulation (VS) in urethane-anesthetized rats was studied using scanning electron microscopy. VS $(1.25-10 \mathrm{~Hz}, 0.2 \mathrm{~mA}, 2 \mathrm{msec}, 10 \mathrm{~min})$ resulted in a graded increase in the SEC damage, increased gastric contractions, increased gastric acid secretion, and a decrease in heart rate. Pretreatment with $\mathrm{dmPGE}_{2}(0.3-30 \mu \mathrm{g} / \mathrm{kg}$, s.c.) significantly protected the SEC from VS-induced damage, inhibited the increase in gastric contractions and acid secretion, but had no influence on the decrease in heart rate. Atropine (1 $\mathrm{mg} / \mathrm{kg}$, s.c.) also protected the SEC from VS-induced damage and inhibited the alterations in response to VS. Timoprazole $(30 \mathrm{mg} / \mathrm{kg}$. s.c.) had no protective effects on SEC from VS-induced damage, no effect on increased gastric contractions and heart rate, but did inhibit the increase in gastric acid secretion, in response to VS. These results suggest that: (A) VS-induced SEC damage was caused by increased gastric contractions and not by increased gastric acid secretion, and (B) dmPGE 2 protects against SEC damage by inhibiting gastric contractions.
\end{abstract}

We reported that neither antisecretory nor non-antisecretory doses or 16,16-dimethyl prostaglandin $E_{2}\left(d m P G E_{2}\right)$ protected the surface epithelial cells (SEC) in the rat stomach from ethanol-induced damage (1). However, we found that $\mathrm{dmPGE}_{2}$, even at non-antisecretory doses, significantly protected the SEC from aspirin- and indomethacin-induced damage $(1,2)$. These results indicate that the effects of dmPGE 2 on SEC damage induced by various agents, which may be a prerequisite for further development of gastric mucosal lesions, are different and inconsistent.

Vagal overactivity has been implicated in the etiology of indomethacin- (3), phenylbutazone- (4) and stress- (5-7) induced gastric ulcers in rats as shown by the protective effects of pretreatment with anti- cholinergics or by vagotomy. Cho et al. ( 8 . 9) examined the direct effect of electrical stimulation of the vagus on the formation of gastric mucosal lesions in urethane-anesthetized rats. They postulated that the increase in intragastric pressure and a release of histamine from the stomach by vagal overactivity are involved in the pathogenesis of lesion formation.

Since prostaglandins inhibit the ulcer formation induced by indomethacin, phenylbutazone or stress, it is of interest to determine whether or not dmPGE 2 can protect the SEC from vagal nerve stimulation (VS)induced damage in rats. To elucidate the mechanism of $\mathrm{dmPGE}_{2}$ protection, atropine (an anticholinergic agent) and timoprazole (a proton pump inhibitor) were used as reference drugs. 


\section{Materials and Methods}

Male Sprague-Dawley rats, weighing 200$240 \mathrm{~g}$. were deprived of food but allowed free access to water for $24 \mathrm{hr}$ prior to the experiments. The animals were anesthetized with urethane $(1.25 \mathrm{~g} / \mathrm{kg}$, i.p., Nakarai) and kept warm with a heating lamp. Tracheal cannulation was then carried out to maintain an open airway.

SEC damage by VS: The left cervical vagal nerve was exposed and cut proximally. Nerve stimulation was carried out at $0.2 \mathrm{~mA}$, square pulse duration of $2 \mathrm{msec}$, and frequency of $1.25,2.5,5$ or $10 \mathrm{~Hz}$ for $10 \mathrm{~min}$ through a bipolar platinum electrode placed distal to the cut on the vagal nerve (Nihon Kohden, SEN-3201). In the sham-operated animals, the vagal nerve was similarly exposed and cut, but stimulation was not given. Immediately after cessation of VS, the stomach was removed and opened along the greater curvature. Scanning electron microscopic study was done as described (1). Briefly, the stomach was extended on a glass plate. washed with saline at $4{ }^{\circ} \mathrm{C}$ and put into phosphate-buffered $1.2 \%$ paraformaldehyde$2.5 \%$ glutaraldehyde- $0.03 \%$ trinitrophenol for $3 \mathrm{hr}$ at $4^{\circ} \mathrm{C}$, then dehydrated using a graded series of ethanol solutions and finally placed in isoamyl acetate. The tissues were then critical point dried with $\mathrm{CO}_{2}$ (Hitachi, HPC-2), mounted on aluminum stubs and vacuum coated with a palladium-platinum ion sputter (Eicho, IB-3). The samples were examined for damage under a scanning electron microscope (JEOL, JSM-T20). Four parts in the corpus were individually scanned. The severity of damage in the SEC was arbitrarily divided into five degrees as follows: Damage index 0 , almost no visible changes in the SEC; damage index 1 , several shallow apical erosions in the SEC: damage index 2, many shallow and several deep apical erosions of the SEC; damage index 3 . many deep apical erosions of the SEC without exposure of lamina propria; damage index 4, focal exfoliation of the SEC, exposing lamina propria; damage index 5 , widespread exfoliation of the SEC and pit cells. The mean values of the four parts of the corpus served as the damage index per stomach.
Each experiment was performed using 5 to 6 rats per group. The person measuring the lesions had no knowledge of which treatment an animal had received.

Gastric acid secretion: To examine the effect of VS on gastric secretion, the following experiments were done. The abdomen was incised and the stomach and duodenum exposed. An acute gastric fistula, prepared by means of a polyethylene tube, was prepared in the forestomach. Another polyethylene tube was inserted into the stomach from a slit on the duodenum and held in place by a ligature around the pylorus. The stomach was perfused at a flow rate of $1.0 \mathrm{ml} / \mathrm{min}$ with saline which was adjusted to $\mathrm{pH} \mathrm{7.0.} \mathrm{gassed}$ with $100 \% \mathrm{O}_{2}$, heated at $37^{\circ} \mathrm{C}$ and kept in a reservoir. Gastric acid secretion was titrated at $\mathrm{pH} 7.0$ using a $\mathrm{pH}$-stat method (Hiranuma, Comtite-8) and by adding $100 \mathrm{mM} \mathrm{NaOH}$ to the reservoir. After stabilization of basal acid secretion, gastric acid secretion was measured every $10 \mathrm{~min}$, before $\mathrm{VS}(1.25-10 \mathrm{~Hz}, 0.2 \mathrm{~mA}$, $2 \mathrm{msec}$ for $10 \mathrm{~min}$ ), during $V S$ and for $60 \mathrm{~min}$ after VS. Six rats per group were used for each experiment.

Gastric motility: Gastric motility was measured using a miniature balloon according to Takeuchi and Nobuhara (10). Briefly, the water-filled balloon and support catheter were inserted into the stomach through a cautery hole made in the forestomach. These were tied in place so that they lay in the glandular part of the stomach, and the system was connected to a pressure transducer (Nihon Kohden, LPU-0.1-350-0-II). The gastric motility was quantitated by both measuring the maximum amplitude of intragastric pressure $\left(\mathrm{cmH}_{2} \mathrm{O}\right)$ and counting the number of spikes with an amplitude of 20 $\mathrm{cmH}_{2} \mathrm{O}$ or greater during VS $(1.25-10 \mathrm{~Hz}$, $0.2 \mathrm{~mA} .2 \mathrm{msec}$ for $10 \mathrm{~min}$ ). Additionally, the left femoral artery was cannulated using a polyethylene tube (Clay Adams, PE-50) to monitor blood pressure with the aid of a pressure transducer (Nihon Kohden, MPU0.5-290-0-1II). Heart rate was measured using a cardiotachometer (Nihon Kohden. AT600 ) triggered by the $R$ wave of the limb lead II electrocardiogram. Five rats per group were used for each experiment.

Drugs: $\mathrm{dmPGE} \mathrm{E}_{2}$ dissolved in triacetin $(2.2$ 
$\mathrm{mg} / \mathrm{ml}$. Funakoshi) was diluted with saline to an appropriate concentration before use. Atropine sulfate (Sigma) was freshly dissolved in saline, and timoprazole, synthesized in the Suntory Laboratory. was suspended in saline with a few drops of Tween 80 (Nakarai). Either dmPGE, $(0.3,3,30 \mu \mathrm{g} / \mathrm{kg})$. atropine $(1 \mathrm{mg} / \mathrm{kg})$, or timoprazole $(30 \mathrm{mg} /$ $\mathrm{kg})$ was given s.c. $30 \mathrm{~min}$ before $V \mathrm{~S}$, in a volume of $0.5 \mathrm{ml} / 100 \mathrm{~g}$ body weight, in all experiments. Control animals were given only the vehicle.

Statistics: Data are presented as the mean \pm S.E., and were analyzed for statistical significance by means of Student's $t$-test and the Fisher Exact test.

\section{Results}

SEC damage by VS: Flectrical stimulation of the vagal nerve at 1.25 to $10 \mathrm{~Hz}, 0.2 \mathrm{~mA}$, $2 \mathrm{msec}$ for $10 \mathrm{~min}$ produced a frequencydependent and significant increase in damage in the SEC of the corpus mucosa (Fig. 1). At $1.25 \mathrm{~Hz}$, the appearance of SEC did not differ from that in the nonstimulated group. However, there was apparent damage in the apical membrane of the SEC when VS was applied at $2.5 \mathrm{~Hz}$. The damage became severe at $5 \mathrm{~Hz}$, i.e., a widespread exfoliation of the SEC and exposure of the lamina propria along the

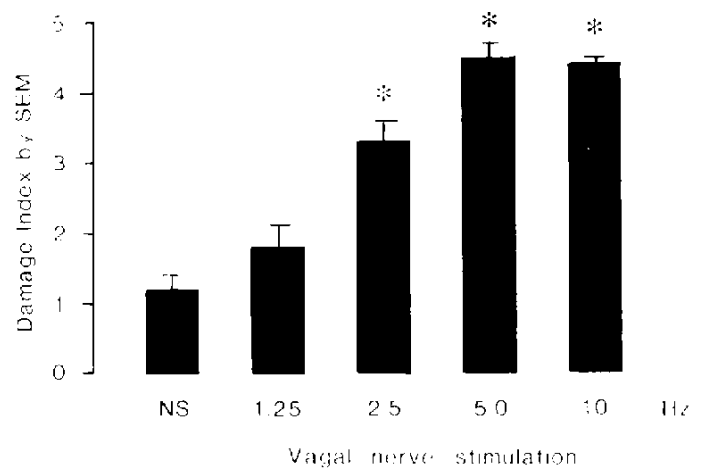

Fig. 1. Effects of vagal nerve stimulation (VS) on surface epithelial celis of the gastric corpus mucosa in urethane-anesthetized rats. VS $(0.2 \mathrm{~mA}, 2 \mathrm{msec}$. $2.5 \mathrm{~Hz}$ or over. $10 \mathrm{~min}$ ) significantly increased the damage index determined by scanning electron microscopy (SEM), as compared to the nonstimulated group (NS). Data represent the mean \pm one S.E. mucosal folds (Fig. 2, A and B, control: C and $D$. VS). The severity of damage after stimulation at $10 \mathrm{~Hz}$ was much the same as observed at $5 \mathrm{~Hz}$. The SEM indices were $4.5 \pm 0.2$ and $4.4 \pm 0.1$ at 5 and $10 \mathrm{~Hz}$, respectively. Therefore, we used the conditions of $5 \mathrm{~Hz}, 0.2 \mathrm{~mA}, 2 \mathrm{msec}$ for $10 \mathrm{~min}$ as the standard stimulation in all the following experiments.

Effects of VS on gastric acid secretion: The mean basal acid output was $3.3 \pm 0.2 \mu \mathrm{Eq} / 10$ $\min (n=30$, Fig. 3 ). VS gradually stimulated gastric acid secretion during and after cessation of VS, in a frequency-dependent manner $(1-5 \mathrm{~Hz})$. However, at $10 \mathrm{~Hz}$, the gastric acid secretion was decreased, as compared with that at $5 \mathrm{~Hz}$ stimulation. This may be due to cardiovascular changes, as mentioned below. The maximal acid output was observed $10 \mathrm{~min}$ after cessation of VS $(18.7 \pm 0.8 \mu \mathrm{Eq} / 10 \mathrm{~min}$ at $5 \mathrm{~Hz})$, and recovery occurred about 90 min after the cessation of VS.

Effects of VS on gastric motility and on the cardiovascular system: VS at 1.25 to $5 \mathrm{~Hz}$ produced a frequency-dependent increase in gastric contractions (both the amplitude and frequency) (Figs. 4A and 5). The increase in the amplitude reached the maximum at $5 \mathrm{~Hz}$ and showed no further increase at $10 \mathrm{~Hz}$, and rather, the frequency of contractions was decreased. The mean arterial blood pressure was not influenced by VS at 1.25 to $5 \mathrm{~Hz}$, but a small reduction in heart rate was observed (Fig. $4 \mathrm{~B}$ ). At $10 \mathrm{~Hz}$, a marked reduction in heart rate (by $131 \pm 36$ / min) and arrhythmias were observed. In particular, the diastolic blood pressure was decreased.

Effects of dmPGE $E_{2}$ atropine and timoprazole on VS-induced SEC damage: Pretreatment with $\mathrm{dmPGE}_{2}$ ( 3 and $30 \mu \mathrm{g} / \mathrm{kg}$ ) significantly protected the SEC from VSinduced damage, as compared to the control value, the protection being $57.8 \%$ and $64.4 \%$, respectively (Fig. 6). Representative microphotographs are shown in Fig. 7. The SEC was also protected from the VS-induced damage by pretreatment with atropine $(1 \mathrm{mg} /$ $\mathrm{kg}$. Fig. 6). The degree of protection (62.3\%) by atropine was all but equal to that observed by $\mathrm{dmPGE}_{2}$ (3 or $30 \mu \mathrm{g} / \mathrm{kg}$. Fig. 7E). In 

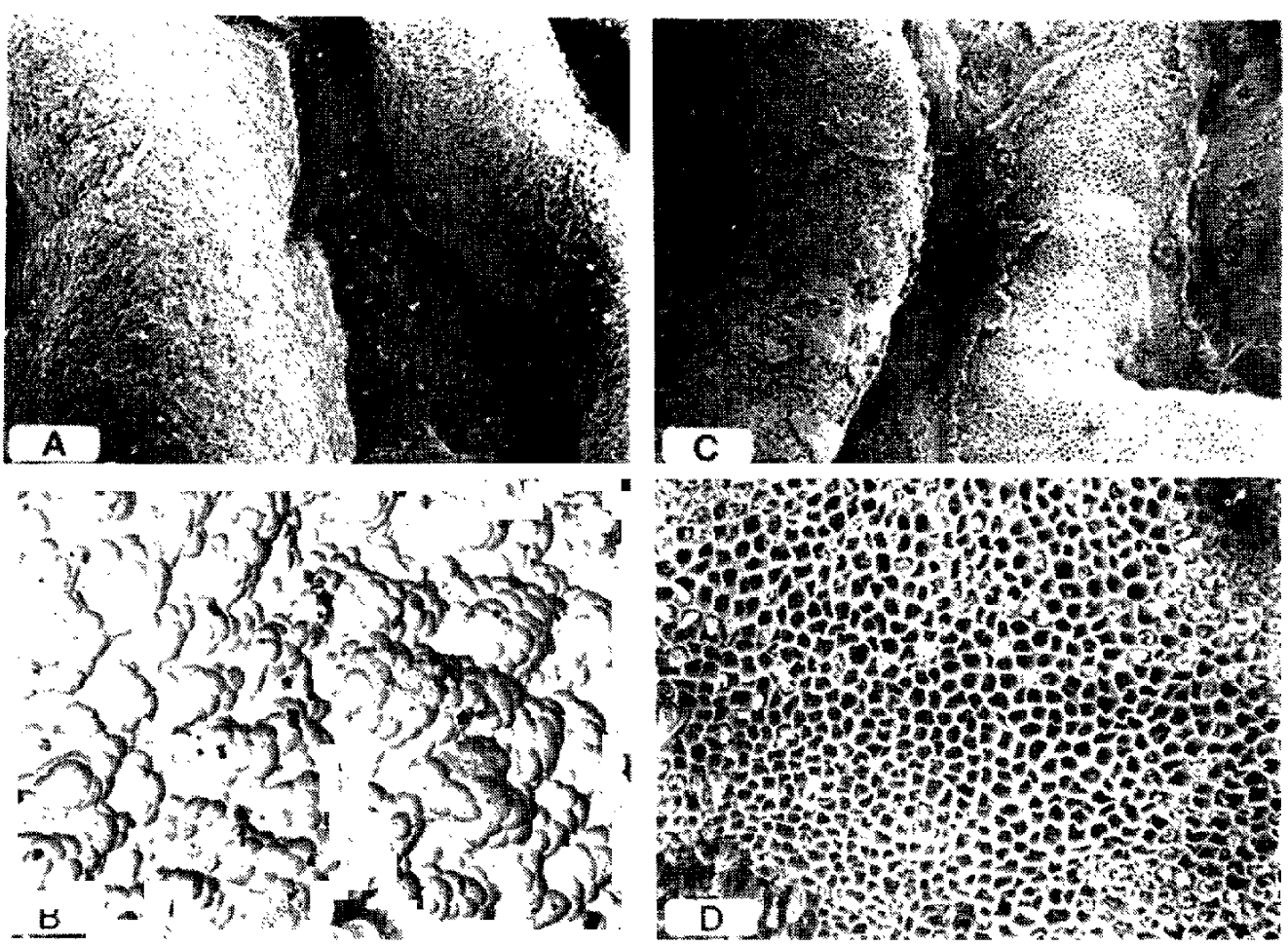

Fig. 2. Scanning electron microphotographs showing the gastric corpus mucosa of sham operated, non-stimulated rats $(\mathrm{A}: \times 30, \mathrm{~B}: \times 500)$ and of $\mathrm{VS}(5 \mathrm{~Hz}, 0.2 \mathrm{~mA}, 2 \mathrm{msec}, 10 \mathrm{~min})$ rats $(\mathrm{C}: \times 30, \mathrm{D}: \times 300)$ anesthetized with urethane. Note that there was a widespread exfoliation of surface epithelial cells on top of the mucosal folds after VS, resulting in an exposure of the lamina propria, as a honey-comb structure.

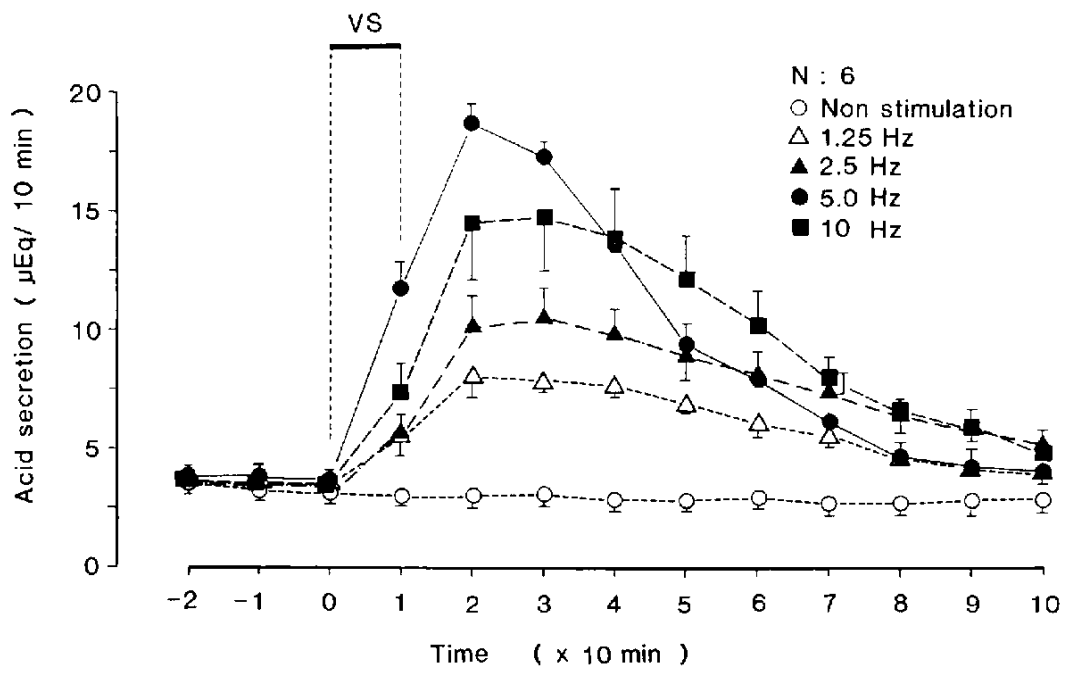

Fig. 3. Effects of VS on gastric acid secretion in urethane-anesthetized rats. Gastric acid output was Hzdependently increased and reached the maximum in the case of $5 \mathrm{~Hz}$. Data represent the meantone $S$. E. 
contrast, pretreatment with timoprazole (30 $\mathrm{mg} / \mathrm{kg}$ ) had no effect on VS-induced damage (Figs. 6 and $7 F$ ).

Effects of dmPGE $E_{2}$, atropine and timoprazole on gastric acid secretion induced by VS: Pretreatment with $d m \mathrm{PGE}_{2}$ inhibited VSinduced acid secretion (both the basal and stimulated), in a dose-dependent manner (Fig. 8). Even at a dose of $0.3 \mu \mathrm{g} / \mathrm{kg}$, there was a significant inhibition of acid secretion for $20 \mathrm{~min}$. At 3 or $30 \mu \mathrm{g} / \mathrm{kg}$, the VS-induced acid secretion was potently inhibited for 60 min after $V S$. Atropine $(1 \mathrm{mg} / \mathrm{kg})$ and timoprazole $(30 \mathrm{mg} / \mathrm{kg})$ also potently inhibited the VS-stimulated acid secretion and the basal and VS-induced acid secretion. respectively (Fig. 8).

Effects of dmPGE 2 , atropine and timoprazole on gastric hypermotility induced by VS: Pretreatment with $\mathrm{dmPGE}_{2}$ significantly reduced the amplitude of the gastric contractions in response to VS (Fig. 9), the inhibition being $22.0 \%, 38.0 \%$ and $60.6 \%$ at $0.3,3$ and $30 \mu \mathrm{gg} / \mathrm{kg}$. respectively. At 30 $\mu \mathrm{g} / \mathrm{kg}$, the frequency of gastric contractions became zero. The decrease in heart rate in response to $V S$ was not affected by dmPGE even at a dose of $30 \mu \mathrm{g} / \mathrm{kg}$ (data not shown). Atropine $(1 \mathrm{mg} / \mathrm{kg}$ ) also significantly inhibited both the amplitude and frequency of gastric contractions, as compared to events
$N: 5$
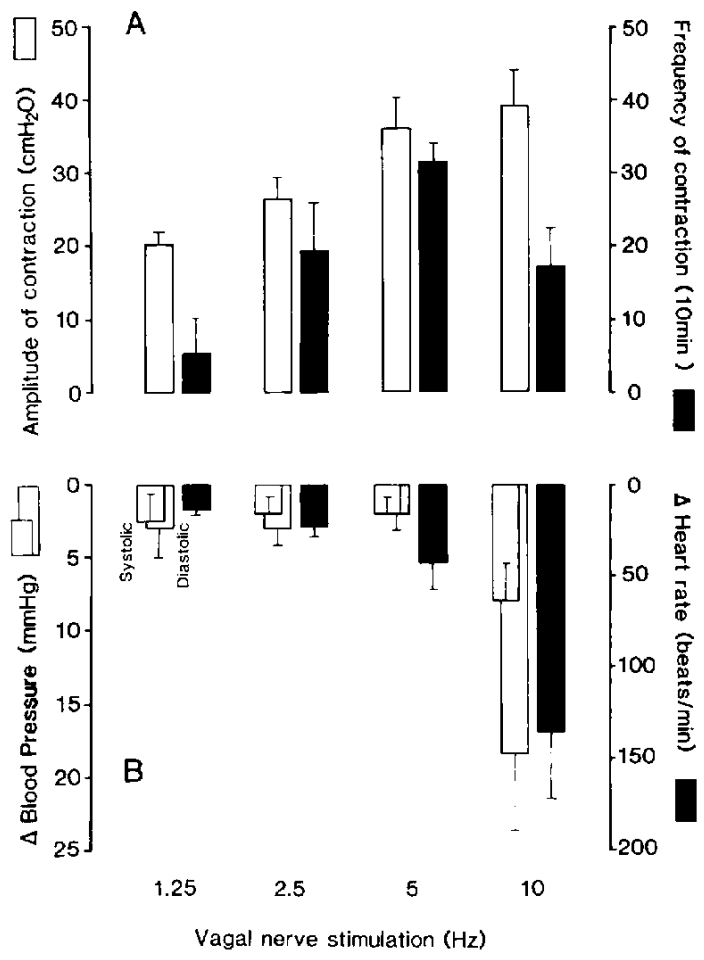

Fig. 4. Effects of VS on gastric contraction (A) and blood pressure and heart rate (B) in urethaneanesthetized rats. Gastric contraction (both amplitude and frequency) was increased in an $\mathrm{Hz}$-dependent manner. Data represent the mean \pm one S.E.

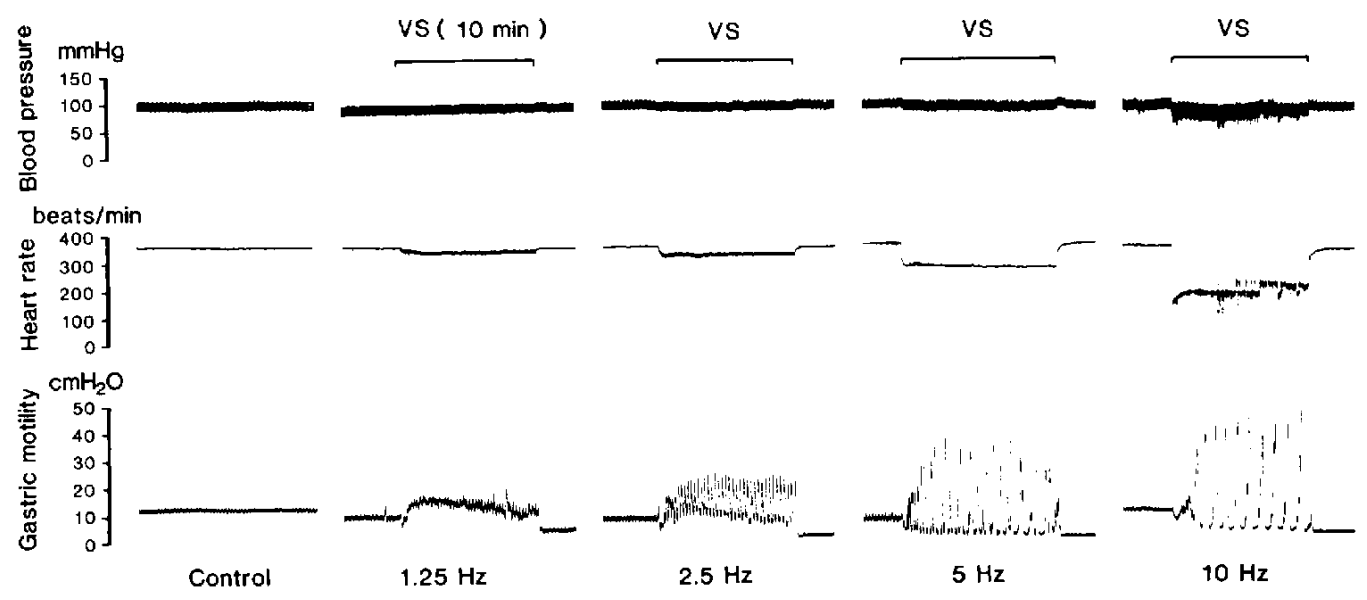

Fig. 5. Representative figures showing the effects of VS $(1.25-10 \mathrm{~Hz}, 0.2 \mathrm{~mA}, 2 \mathrm{msec})$ on gastric contraction, heart rate and blood pressure in a urethane-anesthetized rat. Gastric contraction (both amplitude and frequency) was increased in an $\mathrm{Hz}$-dependent manner and reached the maximum with $5 \mathrm{~Hz}$. 


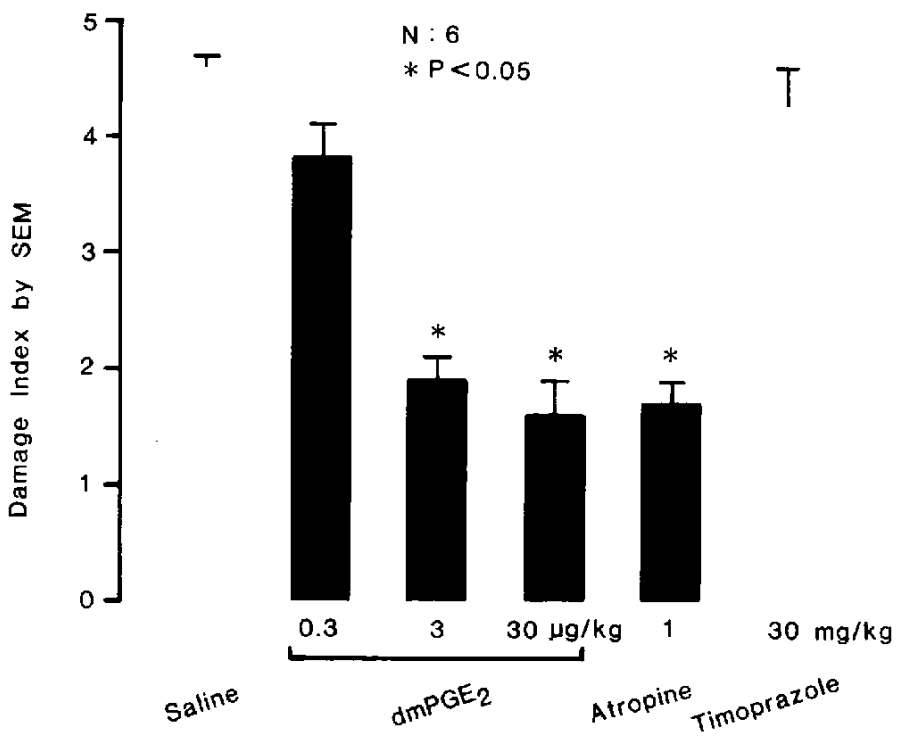

Fig. 6. Effects of dmPGE $E_{2}$, atropine and timoprazole on surface epithelial cell damage induced by $V S$ $(5 \mathrm{~Hz}, 0.2 \mathrm{~mA}, 2 \mathrm{msec}, 10 \mathrm{~min})$ to the gastric corpus mucosa in urethane-anesthetized rats. Both dmPGE and atropine significantly reduced the damage index, determined by scanning electron microscopy (SEM). Timoprazole had no effect on the damage. Data represent the mean \pm one S.E.

observed before VS. The agent attenuated bradycardia in response to VS (data not shown). It is to be noted that timoprazole had no effect on gastric contractions (both amplitude and frequency) and heart rate in response to VS.

\section{Discussion}

We found that electrical stimulation of the vagus nerve for $10 \mathrm{~min}$ induced microscopical damage to the SEC of the gastric corpus of anesthetized rats. The damage mainly consisted of a widespread exfoliation of the SEC and exposure of the lamina propria. These features resemble those observed after intragastric application of 50 or $100 \%$ ethanol (1. 11), aspirin (1) and indomethacin (2. 12). Cho et al. (8) reported the development of macroscopically visible damage of the gastric mucosa after VS ( 2 or $5 \mathrm{~V}, 20 \mathrm{~Hz}, 2$ msec, $2 \mathrm{hr}$ ). In contrast to their findings, we found no visible damage, probably because of the short time and strength of VS. However, the exposure of lamina propria produces a vulnerable stage of gastric mucosa, an event which may be a prerequisite for further development of gastric mucosal lesions.

Cho et al. (8, 9) postulated that VSinduced gastric lesions might be caused by increased contractions of the stomach and not by increased acid secretion. They reported that the VS-induced damage was potently inhibited by pretreatment with atropine and was not inhibited by perfusion of $\mathrm{NaHCO}_{3}$. We also confirmed that ga tric contractions and gastric acid output were significantly increased by VS. Pretreatment with dmPGE 2 and atropine markedly protected the SEC from the VS-induced damage. The doses of these agents were those which significantly inhibited the increased gastric acid secretion and gastric contractions in response to $V S$. dmPGE $E_{2}$ had no effect on the changes in the cardiovascular system in response to VS. Therefore, the pathogenesis of the VS-induced damage appears to involve at least these two parameters.

It was reported that SEC was damaged by acute stimulation of gastric acid secretion by pentagastrin or intra-gastric instillation of $150 \mathrm{mM} \mathrm{HCl}$, when determined in a scanning electron microscopic study of the rat stomach (13). Since VS leads to the release of 
histamine (9) and gastrin (14), the increased acid secretion caused by VS may be due to direct action on parietal cells by a cholinergic mechanism and indirect action through the
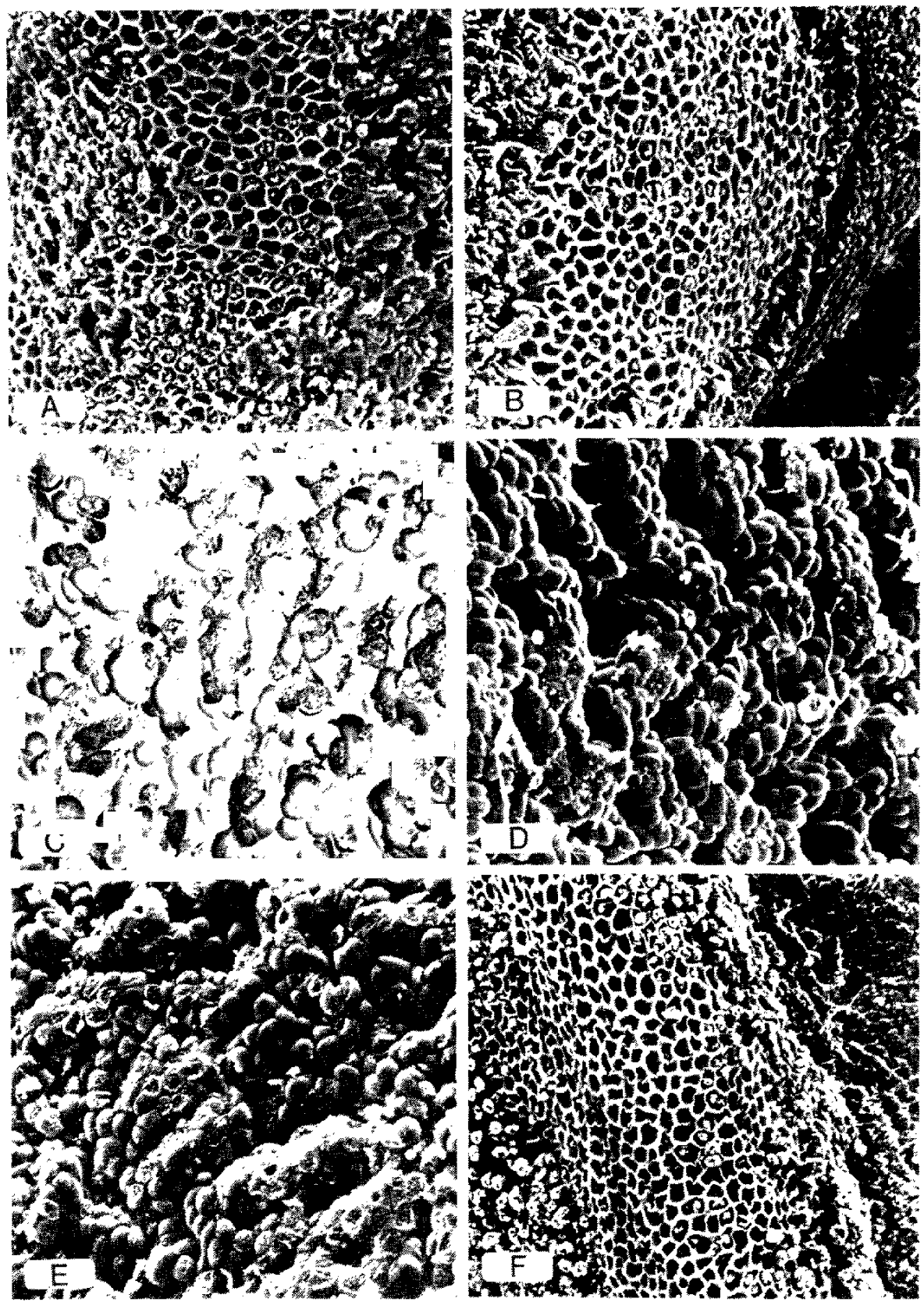

Fig. 7. Scanning electron microphotographs showing the effects of dmPGE 2 , atropine and timoprazole on surface epithelial cell damage induced by VS $(5 \mathrm{~Hz}, 0.2 \mathrm{~mA}, 2 \mathrm{msec}, 10 \mathrm{~min})$ to the gastric corpus mucosa in urethane-anesthetized rats. Note that pretreatments with $\mathrm{dmPG} E_{2}$ and atropine protected the surface epithelial cells against VS-induced damage. Timoprazole had no effect on this damage. A: vehicle alone (x100); B: dmPGE, $0.3 \mu \mathrm{g} / \mathrm{kg}(\times 100) ; \mathrm{C}: \mathrm{dmPGE}, 3 \mu \mathrm{g} / \mathrm{kg}(\times 500): \mathrm{D}: \mathrm{dmPGE}$, $30 \mu \mathrm{g} / \mathrm{kg}(\times 500)$ : E: atropine, $1 \mathrm{mg} / \mathrm{kg}(\times 500) ; \mathrm{F}$ : timoprazole, $30 \mathrm{mg} / \mathrm{kg}(\times 100)$. 

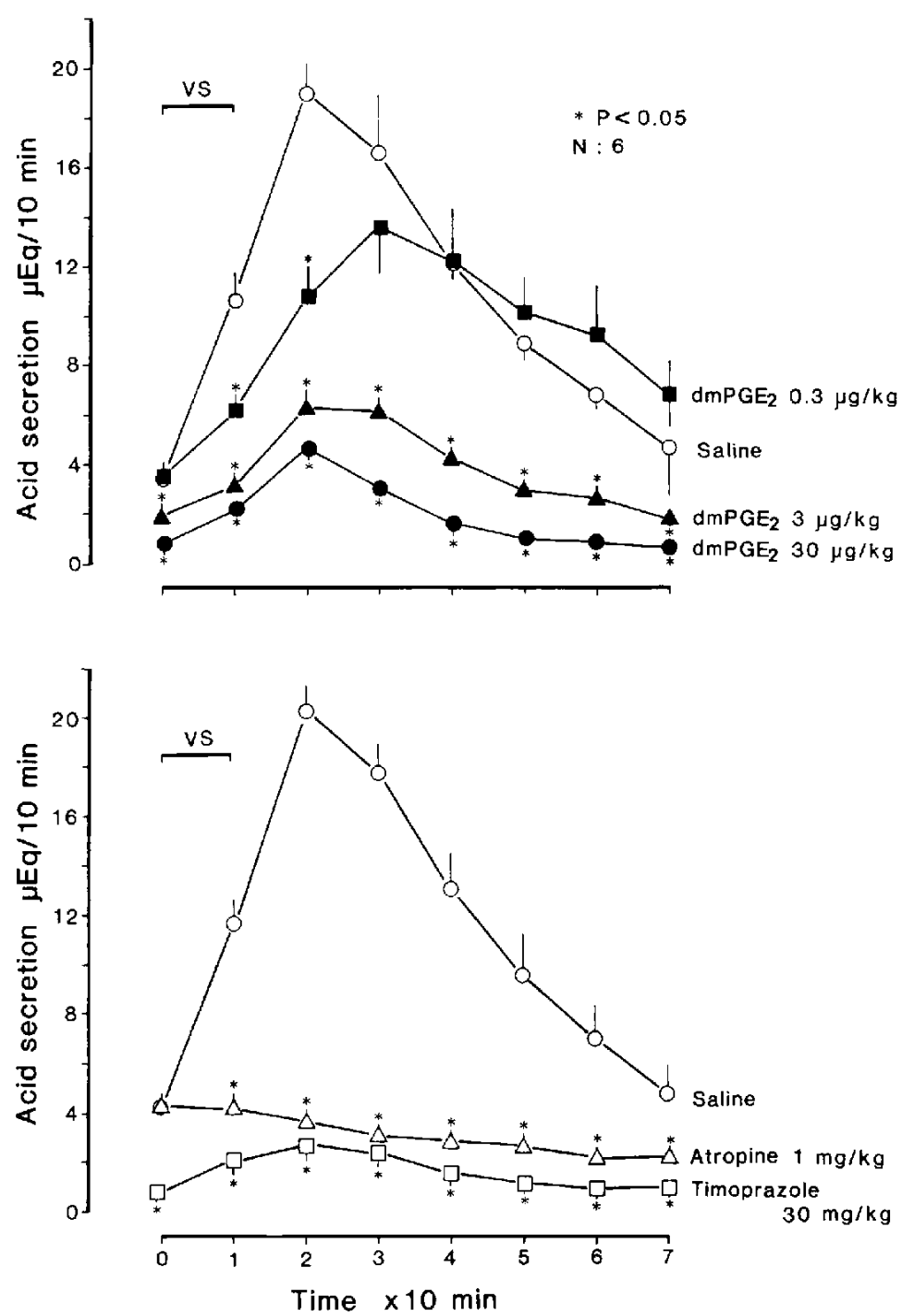

Fig. 8. Effects of dmPGE $0.2 \mathrm{~mA}, 2 \mathrm{msec}, 10 \mathrm{~min}$ ) in urethane-anesthetized rats. Pretreatment with dmPGE 2 and timoprazole inhibited the basal and vagal nerve stimulated acid output. Atropine markedly inhibited the vagal nerve stimulated acid secretion. Data represent the mean \pm one S.E.

release of histamine and gastrin. These findings may account for the increase in acid secretion which persisted after the cessation of VS

Ruwart et al. (15) reported that timoprazole macroscopically protected the gastric mucosa from $100 \%$ ethanol-induced damage. Timoprazole had no protective effect on the SEC damage caused by VS. It is possible that timoprazole, like prostaglandins (1. 16.
17), has no protective effect on the SEC against ethanol-induced damage, as determined microscopically. Timoprazole, like $\mathrm{dmPGE}_{2}$ and atropine, potently inhibited the increased gastric acid output. However, this agent, in contrast to $\mathrm{dmPGE}_{2}$ and atropine. had no effect on VS-induced gastric contractions. These results indicate that $\mathrm{dmPGE}_{2}$ and atropine protected the SEC from VSinduced damage, probably by inhibiting the 

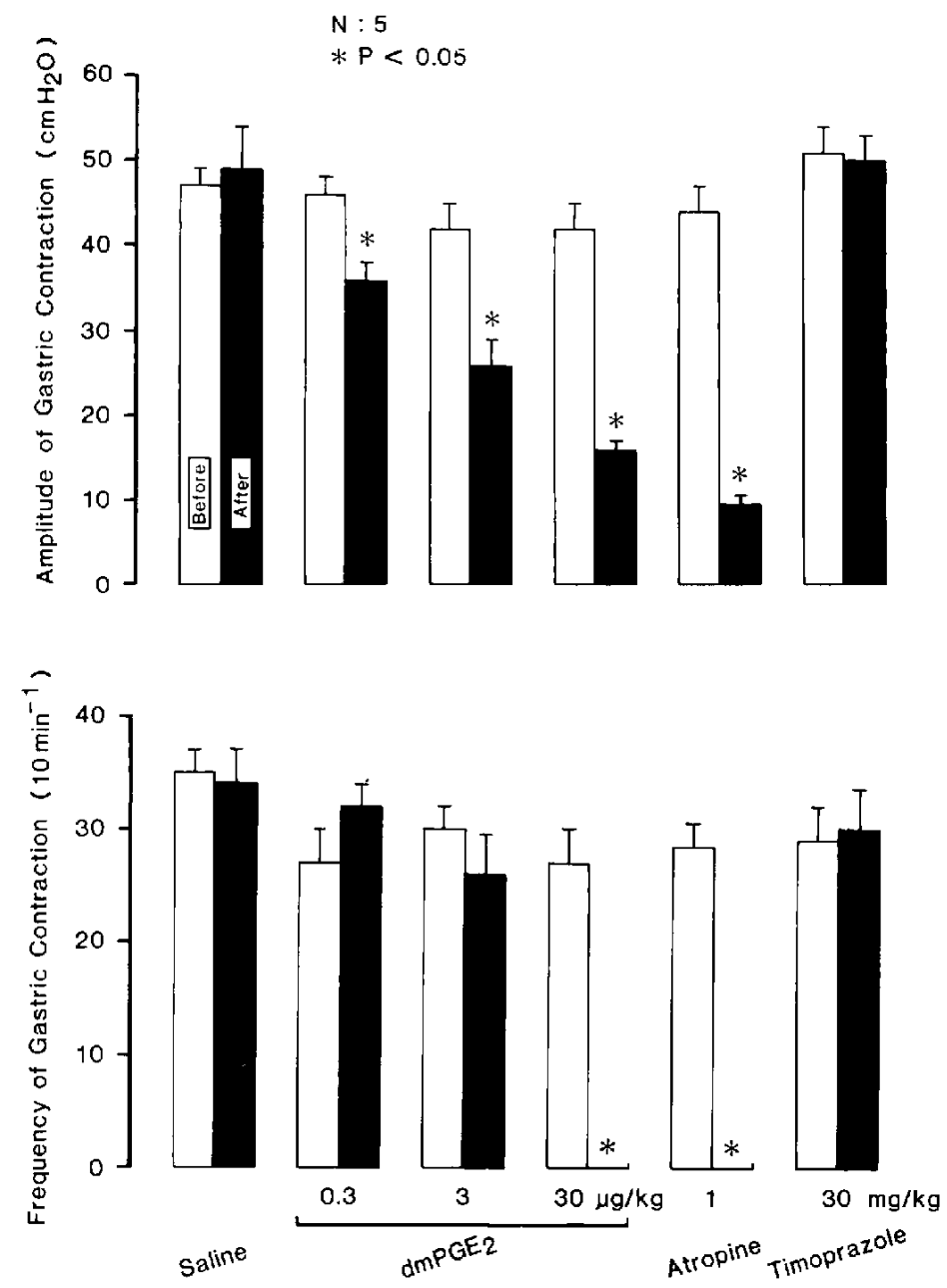

Fig. 9. Effects of $\mathrm{dmPGE}_{2}$, atropine and timoprazole on gastric motility enhanced by VS (5 Hz, $0.2 \mathrm{~mA}$, 2 msec. $10 \mathrm{~min}$ ) in urethane anesthetized rats. Both dmPGE 2 and atropine significantly reduced the increase in gastric contraction (both amplitude and frequency). Timoprazole had no effect on these contractions. Data represent the meantone S.E.

increase in gastric contractions, events which may cause mucosal compression and rubbing. It is known that VS increases gastric mucosal blood flow as well as gastric acid secretion $(18,19)$. However, contractile activity of the serosal musculature may compress the mucosa within the folds and thereby reduce ridge flow (20). Whether or not dmPGE and atropine influence the change in blood flow following $V S$ is the subject of ongoing study.

There are reports dealing with the pathogenesis of indomethacin-induced gastro- intestinal damage, as reviewed by one of the present authors (S.O.) (21). Mersereau and Hinchey (22), Takeuchi et al. (23) and Ohno et al. (2) provided evidence that the pathogenesis of gastric damage induced by indomethacin may involve increased gastric contractions through vagal overactivity. This proposal is supported by the finding that atropine and $\mathrm{PmPGE}_{2}$ at doses which inhibit gastric contractions in response to indomethacin protect the gastric mucosa from indomethacin-induced damage (24). Therefore, the VS- and indomethacin-induced 
damage might share, at least in part, a common genesis. Furthermore, Mersereau and Hinchey $(4,25,26)$ reported that the gastric lesions induced by phenylbutazone and stress were formed at specific sites along the gastric mucosal folds as the results of mucosal compression via vagal overactivity. In the present study. we observed that the exfoliation of SEC after VS was also situated on the crests of the mucosal folds. These results and previous reports taken together indicate that vagal overactivity is implicated in the etiology of indomethacin-, phenylbutazone- and stress-induced gastric ulcers, induces the gastric compression which leads to the exfoliation of SEC, and this vulnerable stage of gastric mucosa develops to visible lesions when other factors are added such as deficiency of endogenous prostaglandins, gastric acid hypersecretion, decrease of mucosal blood flow and so on.

Takeuchi and Nobuhara (10) found that necrotizing agents such as absolute ethanol, $0.6 \mathrm{~N} \mathrm{HCl}, 0.25 \mathrm{~N} \mathrm{NaOH}$ or boiling water markedly increased gastric contractions of rats immediately after intragastric application. Since $d m \mathrm{PGE}_{2}$ at the dose which inhibits increased gastric contractions macroscopically protected the gastric mucosa from necrotizing agent-induced streak lesions. they postulated that protective effects of $\mathrm{dmPGE} 2$ appeared through prevention of contractions and dissolution of the mucosal folds. Unlike VS- or indomethacin-induced damage, dmPGE 2 had no protective effect on the SEC of the gastric mucosa from ethanolinduced damage (1). In the initial stage, mechanisms other than gastric contractions, such as direct physico-chemical invasion to the SEC may be involved in the ethanolinduced gastric mucosal damage.

We conclude that (A) VS induces SEC damage to the gastric mucosa of rats within $10 \mathrm{~min}$ through increased gastric contractions, (B) dmPGE 2 protects the SEC from VS-induced damage, probably by inhibiting these gastric contractions.

\section{References}

1 Ohno, T., Ohtsuki, H. and Okabe, S.: Effects of 16,16-dimethyl prostaglandin $E_{2}$ on ethanolinduced and aspirin-induced gastric damage in the rat. Gastroenterology 88, 353-361 (1985)

2 Ohno, T., Yamamoto, K., Takeuchi, K. and Okabe, S.: 16,16-Dimethyl prostaglandin $E_{2}$ protects rat gastric mucosal cells from damage induced by indomethacin. Japan. J. Pharmacol. 43, 213-220 (1987)

3 Kasuya, Y., Urushidani, T. and Okabe, S.: Effects of various drugs and vagotomy on indomethacin-induced gastric ulcers in the rat. Japan. J. Pharmacol. 29, 670-673 (1979)

4 Mersereau, W.A. and Hinchey, E.J.: Synergism between acid and gastric contractile activity in the genesis of ulceration and hemorrhage in the phenylbutazone-treated rat. Surgery 90, 516 522 (1981)

5 Watanabe, K.: Some pharmacological factors involved in formation and prevention of stress ulcers in rats. Chem. Pharm. Bull. (Tokyo) 14, 101-107 (1966)

6 Goldman, H. and Rosoff, C.B.: Pathogenesis of acute gastric stress ulcers. Am. J. Pathol. 52, 227-244 (1968)

7 Dai, S. and Ogle, C.W.: Gastric ulcers induced by acid accumulation and by stress in pylorus occluded rats. Eur. J. Pharmacol. 26, 15-21 (1974)

8 Cho, C.H., Ogle, C.W. and Dai, S.: Acute gastric ulcer formation in response to electrical vagal stimulation in rats. Eur. J. Pharmacol. 35, $215-$ $219(1976)$

9 Cho, C.H., Hung, K.M. and Ogle, C.W.: The aetiology of gastric ulceration induced by electrical vagal stimulation in rats. Eur. J. Pharmacol. 110, 211-217 (1985)

10 Takeuchi, $K$. and Nobuhara, $Y$.: Inhibition of gastric motor activity by 16,16-dimethyl prostaglandin $E_{2}$; A possible explanation of cytoprotection. Dig. Dis. Sci. 30, 1181-1188 (1985)

11 Tarnawski, S., Hollander, D., Stachura, J., Krause, W.J. and Gergely, H.: Prostaglandin protection of the gastric mucosa against alcohol injury-A dynamic time-related process. Gastroenterology 88, 334-352 (1985)

12 Ohtsuki, H., Yamamoto, O. and Okabe, S.: Scanning electron microscopic studies of cytoprotection by $16-\mathrm{dmPGE}_{2}$ on indomethacininduced gastric and intestinal lesions in rats. $/ n$ Mechanisms of Mucosal Protection in the Upper Gastrointestinal Tract, Edited by Allen, A., Garner, A., Flemstrom, G., Turnberg, L. and Silen, W., p. 371-376, Raven Press, New York (1984)

13 Wood, L.R. and Dubois, A.: Scanning electron microscopy of the stomach during modifications of acid secretion. Am. J. Physiol. 244, G475 
G479 (1983)

14 Feldman, M. and Richardson, C.T.: Gastric acid secretion in humans. In Physiology of the Gastrointestinal Tract, Edited by Johnson, L.R., p. 698-699, Raven Press, New York (1983)

15 Ruwart, M.J., Lancaster, C., Nezamis, J.E., Davis, J.P., Rush, B.D., Friedle, N.M. and Pugh, C.: Timoprazole: a unique antisecretory and $\mathrm{Cy}$ toprotective agent. Gastroenterology (Abstract) 82, 1166 (1982)

16 Lacy, E.R. and Ito, S.: Microscopic analysis of ethanol damage to rat gastric mucosa after treatment with a prostaglandin. Gastroenterology $83,619-625(1982)$

17 Wallace, J.L., Morris, G.P., Krausse, E.J. and Greaves, S.E.: Reduction by cytoprotective agents of ethanol-induced gastric mucosal damage: A correlated morphological and physiological study. Can. J. Physiol. Pharmacol. 60, 1686-1699 (1982)

18 Guth, P.H. and Smith, E.: Neural control of gastric mucosal blood flow in the rat. Gastroenterology 69, 935-940 (1975)

19 Yokotani, K., Muramatsu, I., Fujiwara, M. and Osumi, Y.: Effects of the sympathoadrenal system an vagally induced gastric acid secretion and mucosal blood flow in rats. J. Pharmacol. Exp. Ther. 224, 436-442 (1983)
20 Larsen, K.R. and Moody, F.G.: Functional difference between ridges and valleys in gastric mucosai rugae. Surgery 91, 243-244 (1982)

21 Okabe, S., Tabata, K. and Ishihara, Y.: Indomethacin: its irritative activity on the gastrointestinal tract of experimental animals. In Drugs and Peptic Ulcer II, Edited by Pfeiffer, C.J., p. 25-42, CRC Press, Boca Raton (1982)

22 Mersereau, W.A. and Hinchey, E.J.: Inhibition of indomethacin induced gastric hypercontractility: A mucosal protective mechanism of prostaglandin $E_{2}$. Gastroenterology (Abstract) 78. 1221 (1980)

23 Takeuchi, K., Ueki, S. and Okabe, S.: Importance of gastric motility on pathogenesis of indomethacin-induced gastric lesions in rats. Dig. Dis. Sci. 31, 1114-1122 (1986)

24 Ueki, S., Takeuchi, K. and Okabe, S.: Gastric motility is an important factor in pathogenesis of indomethacin-induced gastric mucosal lesions in rats. Dig. Dis. Sci. (in press)

25 Mersereau, W.A. and Hinchey, E.J.: Hypothermiainduced gastric hypercontractility in the genesis of the restraint ulcer. Can. J. Surg. 24, 622-625 (1981)

26 Mersereau, W.A. and Hinchey, E.J.: Role of gastric mucosal folds in formation of focal ulcers in the rat. Surgery $91,150-155$ (1982) 